Check for updates

Cite this: J. Mater. Chem. A, 2020, 8 , 20687

Received 3rd August 2020

Accepted 13th September 2020

DOI: $10.1039 / \mathrm{d} 0 \operatorname{ta} 07600 \mathrm{~g}$

rsc.li/materials-a

\section{The effect of nanoscaffold porosity and surface chemistry on the Li-ion conductivity of $\mathrm{LiBH}_{4}-$ $\mathrm{LiNH}_{2} /$ metal oxide nanocomposites $\uparrow$}

\author{
Laura M. de Kort, (D) Justine Harmel, Petra E. de Jongh and Peter Ngene (DD *
}

Solid-state electrolytes are crucial for the realization of safer batteries with improved capacity. Lithiumbased complex hydrides, for instance $\mathrm{LiBH}_{4}$, display promising characteristics as solid-state electrolytes. However, increasing their low room temperature conductivity $\left(10^{-8} \mathrm{~S} \mathrm{~cm}^{-1}\right.$ for $\left.\mathrm{LiBH}_{4}\right)$ is a prerequisite for application. Partial ionic substitution of $\mathrm{BH}_{4}{ }^{-}$with $\mathrm{NH}_{2}{ }^{-}$followed by nanoconfinement in mesoporous oxide scaffolds increases the conductivity to $5 \times 10^{-4} \mathrm{~S} \mathrm{~cm}^{-1}$. Here, we show that the conductivity of $\mathrm{LiBH}_{4}-\mathrm{LiNH}_{2} /$ metal oxide nanocomposites is strongly influenced by the chemical and physical nature of the scaffold material. By tuning both the surface chemistry and the pore structure, the conductivity can be varied by three orders of magnitude at room temperature. Unexpectedly, even though a significant influence of the scaffold surface chemistry is observed, the nanocomposite conductivity is largely dictated by the scaffold pore volume. This is in contrast to nanoconfined pure $\mathrm{LiBH}_{4}$, where the conductivity is governed by the chemical nature of the mesoporous scaffold. For nanoconfined $\mathrm{LiBH}_{4}-\mathrm{LiNH}_{2}$, the conductivity improvement is attributed to stabilization of a highly conductive phase inside the scaffold pores, rather than the formation of a conductive interfacial layer at the oxide/hydride interface as observed for nanoconfined $\mathrm{LiBH}_{4}$. These findings could be applicable to other cation- and anion-substituted nanocomposites and provide a useful tool to develop novel solidstate electrolytes with excellent ionic conductivities.

\section{Introduction}

Next generation batteries, such as all-solid-state (ASS) batteries, could play a key role in meeting the world's energy storage demands. Both the progressive depletion of fossil fuels and the United Nations' sustainable development goals call for a transition to renewable energy sources. Most renewables, in particular wind and solar energy, are intermittent in nature and, consequently, an increased use of renewable energy calls for improved energy storage devices. ${ }^{1-3}$ All-solid-state batteries are expected to be one of the key storage technologies, both for mobile applications as well as large-scale grid storage. ${ }^{\mathbf{1 , 4}}$ Hence, this battery type could be essential for the transition from fossil fuels to renewable energies.

All-solid-state batteries contain an inorganic or polymeric solid as the electrolyte instead of a solution of an ion conducting salt in organic solvent as is the case for conventional Li-

Inorganic Chemistry and Catalysis Debye Institute for Nanomaterials Science, Utrecht University, Universiteitsweg 99, 3584CG Utrecht, the Netherlands.E-mail: P.Ngene@ uu.nl

$\dagger$ Electronic supplementary information (ESI) available: Synthesis procedure of mesoporous oxides, weight- and molar percentage of all samples; additional XRD, DRIFTS and DSC results of all solid solutions and nanocomposites; nitrogen physisorption of mesoporous oxides; additional conductivity data, including correlations with pore structure. See DOI: 10.1039/d0ta07600g ion batteries. Solid electrolytes are often safer than the volatile and combustible liquid electrolytes, and in many cases they are compatible with high capacity electrodes. ${ }^{5,6}$ This means that the development of ASS batteries can potentially lead to safer batteries that store more energy.

Solid-state electrolytes with good ionic conductivity at ambient temperature as well as good electrochemical stability are crucial for the implementation of ASS batteries. Various classes of materials, including garnets, sulphides, perovskites and complex hydrides, are being investigated as potential solid electrolyte for ASS batteries. ${ }^{7-11}$ Over the past years research has largely focussed on the development of suitable oxide and sulphide-type ion conductors. However, the discovery of unexpectedly fast ion conduction in lithium borohydride initiated research on complex hydride-based solid electrolytes. ${ }^{\mathbf{1 2 - 1 8}}$ Essential to this development was the observation of high lithium-ion mobility $\left(\sim 10^{-3} \mathrm{~S} \mathrm{~cm}^{-1}\right)$ in $\mathrm{LiBH}_{4}$ after a reversible phase change from orthorhombic to hexagonal phase at $110{ }^{\circ} \mathrm{C}^{\mathbf{1 4}}$ Due to their low density, a good electrochemical stability window (up to $\sim 3 \mathrm{~V} v s$. $\mathrm{Li} / \mathrm{Li}^{+}$) and the ability to form a good interface with electrode materials, complex hydrides are promising candidates for application in ASS batteries. ${ }^{\text {19-22 }}$ A main disadvantage remains their moderate room temperature ionic conductivity (for $\mathrm{LiBH}_{4}$ about $10^{-8} \mathrm{~S} \mathrm{~cm}^{-1}$ ). Therefore, the 
development of strategies that enhance conductivity in complex hydrides at ambient temperature is of major importance.

Two promising strategies are being explored. The most common method, partial ionic substitution, is based on replacing some borohydride anions with different anions (e.g. $\mathrm{I}^{-}, \mathrm{Cl}^{-}$or $\left.\mathrm{NH}_{2}{ }^{-}\right){ }^{23-31}$ This leads to stabilization of the highly conductive hexagonal phase at lower temperatures $\left(e . g\right.$. for $\mathrm{I}^{-}$, $\left.\mathrm{Cl}^{-}\right)^{25,30}$ and/or the formation of a new highly conductive phase (e.g. for $\left.\mathrm{NH}_{2}{ }^{-}\right){ }^{27,29}$ Similarly, successful enhancement of conductivity has been achieved through partial cationic substitution of $\mathrm{Li}^{+}$by, for example, $\mathrm{K}^{+}, \mathrm{Ca}^{2+}$ and $\mathrm{La}^{3+} \cdot{ }^{32-34}$ The incorporation of a substituting anion increases the distance between neighbouring $\mathrm{BH}_{4}{ }^{-}$ions, weakens the Coulomb interactions and consequently results in enhanced Li-ion mobility.

In the second method, the lithium salt is intimately mixed with a high surface area non-conducting oxide scaffold, such as $\mathrm{SiO}_{2}$ or $\mathrm{Al}_{2} \mathrm{O}_{3} \cdot{ }^{35-44}$ Close contact can be achieved through nanoconfinement by melt infiltration of the metal hydride in the nanopores of the oxide, thereby forming a nanocomposite. ${ }^{45}$ Interestingly, this method was originally used to improve hydrogen sorption properties of metal hydrides. ${ }^{\mathbf{4 6 - 5 0}}$ Recently, it was discovered that it leads to enhanced Li-ion mobility as well. ${ }^{35}$ The enhancement in ionic conductivity is attributed to the formation of a highly conductive interface layer at the interface of the ion-conducting salt and the insulating scaffold. In general, it is believed that the interaction of the hydride with the scaffold either leads to the formation of a new compound, or a highly defected phase, or that interfacial space charge zones play a role as observed in binary mixtures of metal halides (LiI, LiBr, AgI, etc.) and metal oxides. ${ }^{39,51,52}$

Recently, both methods, viz. partial ionic substitution and nanoconfinement, were successfully combined. In fact, via the synthesis of nanoconfined anion-substituted complex hydrides, such as nanoconfined $\mathrm{LiBH}_{4}-\mathrm{LiI}$ and $\mathrm{LiBH}_{4}-\mathrm{LiNH}_{2}$, conductivity could be substantially improved. ${ }^{53-55}$ Although the increased conductivity in the anion-substituted/oxide nanocomposites was attributed to the synergetic effect of anion substitution and confinement in the oxide nanopores, the exact role of the confinement remained unclear. For nanocomposites with pure complex hydrides, e.g. $\mathrm{LiBH}_{4} / \mathrm{SiO}_{2}$, it is known that their ionic conductivity is greatly affected by the surface properties of the scaffold, such as the nature and density of the surface groups. ${ }^{\mathbf{4 0 - 4 4}}$ For nanoconfined anion-substituted metal hydrides, on the other hand, the impact of the mesoporous scaffold properties on the scaffold/hydride interactions, and consequently ion mobility in the nanocomposites, have not yet been investigated.

In this work, we aim to bridge the knowledge gap by studying the effect of the chemical nature and physical properties (surface area, pore size and pore volume) of different porous, high surface area materials, on the conductivity of $\mathrm{LiBH}_{4}-$ $\mathrm{LiNH}_{2}$ /oxide nanocomposites. To this end, we prepared nanoconfined $\mathrm{LiBH}_{4}-\mathrm{LiNH}_{2}$ using $\mathrm{SiO}_{2}$ scaffolds with varying pore structure and surface properties, as well as mesoporous $\gamma-\mathrm{Al}_{2} \mathrm{O}_{3}$, and studied the influence of the scaffold's properties on the conductivity.

\section{Experimental}

\section{Scaffold synthesis}

Mesoporous silica (MCM-41 and SBA-15) and aluminated silica (Al-SBA-15) were synthesized following the procedures described by Cheng et al., ${ }^{56}$ Lee et $a l .{ }^{57}$ and Baca et al. ${ }^{58} \mathrm{~A}$ complete description of the experimental procedures can be found in the ESI. $\dagger$ Note that Al-SBA-15 with a Si/Al ratio of $20: 1$ and 10:1 were prepared, further referred to as $\mathrm{Al}(20)$ - and $\mathrm{Al}(10)-\mathrm{SBA}-15$. Alumina $\left(\gamma-\mathrm{Al}_{2} \mathrm{O}_{3}\right.$, Puralox SCCa-5/200, $\left.>98.0 \%\right)$ was purchased from Sasol. All scaffolds were dried under vacuum at $150-250{ }^{\circ} \mathrm{C}$ overnight and transferred to an argonfilled glovebox before use.

\section{Nanocomposite synthesis}

Nanocomposites were prepared via a two-step synthesis consisting of the preparation of $\mathrm{LiBH}_{4}-\mathrm{LiNH}_{2}$ phase mixtures followed by melt infiltration of the as-prepared phase mixture. All storage and handling of the chemicals and prepared samples was done in an argon-filled glovebox $\left(\mathrm{H}_{2} \mathrm{O} \& \mathrm{O}_{2}<0.1 \mathrm{ppm}\right)$.

Several $\mathrm{LiBH}_{4}-\mathrm{LiNH}_{2}$ phase mixture were prepared by physically mixing $\mathrm{LiBH}_{4}$ ( $\geq 95 \%$, Sigma-Aldrich) and 5, 15, 25, 30, 40, 50, 67 and 75 molar percentage of $\mathrm{LiNH}_{2}$ (95\%, Sigma-Aldrich). The physical mixture was transferred to a stainless-steel reactor which is then placed in a stainless-steel high-pressure autoclave (Parr, $250 \mathrm{~mL}$ ). The mixture was allowed to react at $150{ }^{\circ} \mathrm{C}$ (heating rate $2.5{ }^{\circ} \mathrm{C} \min ^{-1}$ ) under 50 bar $\mathrm{H}_{2}$ pressure for 30 minutes. After the reaction, the formed phase mixture was ground to fine powders.

Preparation of the $\mathrm{LiBH}_{4}-\mathrm{LiNH}_{2} /$ metal oxide nanocomposites and $\mathrm{LiBH}_{4} /$ metal oxide nanocomposites was achieved via melt infiltration following the procedure of Ngene et $a{ }^{48}$ In general, the $\mathrm{LiBH}_{4}-\mathrm{LiNH}_{2}$ phase mixture (or pure $\mathrm{LiBH}_{4}$ ) was mixed with the appropriate amount of the chosen scaffold in order to fill the scaffold pores by (typically) 130 volume percent. In this way, the $\mathrm{LiBH}_{4}$ content is $30 \mathrm{vol} \%$ larger than the total pore volume of the scaffold material. This ensures a percolating network of fast $\mathrm{Li}^{+}$diffusion pathways over the non-conducting oxide particles. In other words, $\mathrm{Li}^{+}$transport occurs through the metal hydride phase, not through the oxide. The corresponding molar and mass fractions of the composites are provided in Table $\mathrm{S} 1 . \dagger$ The mixture was transferred to a stainless-steel reactor, which was placed in a stainless-steel high-pressure autoclave (Parr, $250 \mathrm{~mL}$ ). The autoclave was pressurized with 50 bar $\mathrm{H}_{2}$ and melt infiltration was carried out for 30 minutes at $120{ }^{\circ} \mathrm{C}$ (heating rate $2.5{ }^{\circ} \mathrm{C} \mathrm{min}^{-1}$ ) for $\mathrm{LiBH}_{4}-$ $\mathrm{LiNH}_{2}$ and at $285{ }^{\circ} \mathrm{C}$ for $\mathrm{LiBH}_{4}$. Upon cooling, the molten $\mathrm{LiBH}_{4}-\mathrm{LiNH}_{2}$ mixture solidifies in the pores of the scaffold material to form nanoconfined $\mathrm{LiBH}_{4}-\mathrm{LiNH}_{2}$ or nanoconfined $\mathrm{LiBH}_{4}$.

\section{General characterization}

X-ray diffraction (XRD) was performed with a Bruker-AXS D8 Advance X-ray diffractometer with Co $\mathrm{K} \alpha 1,2$ radiation $(\lambda=$ $1.78897 \AA$ ). The samples were placed in an airtight sample holder. Diffractograms were recorded at room temperature 
from 20 to $80^{\circ} 2 \theta$. Diffuse reflectance infrared Fourier transform spectroscopy (DRIFTS) measurements were performed on a PerkinElmer 2000 spectrometer equipped with a MCT detector. The sample was placed in an airtight sample holder with $\mathrm{KBr}$ windows. Spectra were acquired from $900 \mathrm{~cm}^{-1}$ to $4500 \mathrm{~cm}^{-1}$ with a resolution of $4 \mathrm{~cm}^{-1}$. Differential scanning calorimetry (DSC) was conducted using a Mettler Toledo HP DSC 1-STAR. About $10 \mathrm{mg}$ of sample was placed in a $40 \mu \mathrm{L} \mathrm{Al}$ sample pan. The measurement was performed under 2 bar $\mathrm{Ar}$

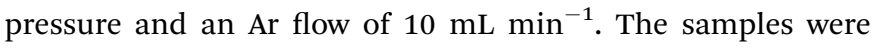
cycled between $30{ }^{\circ} \mathrm{C}$ and $300{ }^{\circ} \mathrm{C}$ with a heating rate of $5{ }^{\circ} \mathrm{C} \mathrm{min}{ }^{-1}$ and a cooling rate of $10{ }^{\circ} \mathrm{C} \mathrm{min}{ }^{-1}$. Nitrogen physisorption measurements were carried out at $-196{ }^{\circ} \mathrm{C}$ on a Micrometritics TriStar II Plus Surface Area and Porosity analyser. No drying procedure was performed prior to the measurements, as all measured samples were stored under controlled atmosphere in an argon-filled glovebox. Analysis of the adsorption and desorption curves was performed following Brunauer, Emmett and Teller (BET) theory and Barrett, Joyner and Halenda $(\mathrm{BJH})$ theory to determine surface area and pore size distribution, respectively. ${ }^{59,60}$

\section{Conductivity measurements}

Electrochemical impedance spectroscopy measurements were performed using a Princeton Applied Research Parstat 2273 connected to a custom-made measurement cell in a Büchi B-585 glass oven placed in an argon-filled glovebox to avoid air and moisture exposure. Symmetrical pellets were prepared by firstly placing lithium foils on top of two stainless steel cylinders $(\varnothing=$ $13 \mathrm{~mm}$ ). Using a standard pellet press, about 80-200 $\mathrm{mg}$ sample was pressed between these cylinders with a pressure of 1.5 ton $\mathrm{cm}^{-2}$. The same pressure was applied for all measurements to minimize differences in void fraction between pellets, which was generally below $20 \%$. The prepared pellet was placed in the measurement cell. In a typical conductivity measurement, the pellet is incrementally heated to $50{ }^{\circ} \mathrm{C}\left(\Delta T=5{ }^{\circ} \mathrm{C}\right)$ and incrementally cooled to room temperature $\left(\Delta T=10^{\circ} \mathrm{C}\right)$. At each increment, the temperature was allowed to equilibrate for 35 min, after which an EIS measurement was performed using a 1.0 V RMS modulated AC potential with frequencies from 1 $\mathrm{MHz}$ to $1 \mathrm{~Hz}$. The Nyquist plots obtained from the data were fitted using an equivalent circuit consisting of a resistance and a constant phase element. The intersection of the fitted semicircle with the $Z_{\text {real }}$ axis was assumed to represent the electrolyte resistance $R$. See Fig. S1 and $\mathrm{S} 2$ in the ESI $\dagger$ for exemplary Nyquist plots of each studied system. Following $\sigma=t /(A R)$, the conductivity $\sigma$ of the solid electrolytes could be calculated using the electrolyte thickness $t$ and geometric surface area $A$ of the electrodes.

\section{Results and discussion}

\section{Partial ionic substitution of $\mathrm{BH}_{4}{ }^{-}$with $\mathrm{NH}_{2}{ }^{-}$}

First, the structural properties of $\mathrm{LiBH}_{4}-\mathrm{LiNH}_{2}$ mixtures containing 15 to $67 \mathrm{~mol}^{2} \mathrm{LiNH}_{2}$ are discussed. The composition of all compounds in wt\% is given in Table S1. $\dagger$ In Fig. 1a the XRD diffraction patterns of $\mathrm{LiBH}_{4}-\mathrm{LiNH}_{2}$ containing 15, 40 and 67\% $\mathrm{LiNH}_{2}$ are presented. For comparison, the XRD patterns of $\mathrm{LiBH}_{4}$ and $\mathrm{LiNH}_{2}$ are included. A complete overview of the XRD data of all prepared $\mathrm{LiBH}_{4}-\mathrm{LiNH}_{2}$ mixtures can be found in Fig. S3. $\uparrow$ The diffraction patterns of the mixtures clearly display features that do not correspond to the starting materials. New reflections are observed, which correspond to the presence of several $\mathrm{LiBH}_{4}-\mathrm{LiNH}_{2}$ phases, such as $\mathrm{Li}_{2}\left(\mathrm{BH}_{4}\right)\left(\mathrm{NH}_{2}\right), \mathrm{Li}_{3}\left(\mathrm{BH}_{4}\right)(-$ $\left.\mathrm{NH}_{2}\right)_{2}$ and $\mathrm{Li}_{4}\left(\mathrm{BH}_{4}\right)\left(\mathrm{NH}_{2}\right)_{3}$. This is in accordance with previously reported results. ${ }^{27,29,61-63}$ Meisner et al. identified four different $\mathrm{LiBH}_{4}-\mathrm{LiNH}_{2}$ phases with different lattice symmetry and varying melting points of $\sim 45{ }^{\circ} \mathrm{C}(\gamma$-phase $), 75-90{ }^{\circ} \mathrm{C}(\beta$-phase $)$, 150-190 ${ }^{\circ} \mathrm{C}\left(\alpha\right.$-phase) and $\sim 50{ }^{\circ} \mathrm{C}(\delta$-phase $) .{ }^{62}$ In our case, the presence of multiple phases in most $\mathrm{LiBH}_{4}-\mathrm{LiNH}_{2}$ mixtures is clearly observed as well. The formation of $\mathrm{LiBH}_{4}-\mathrm{LiNH}_{2}$ phases (a)

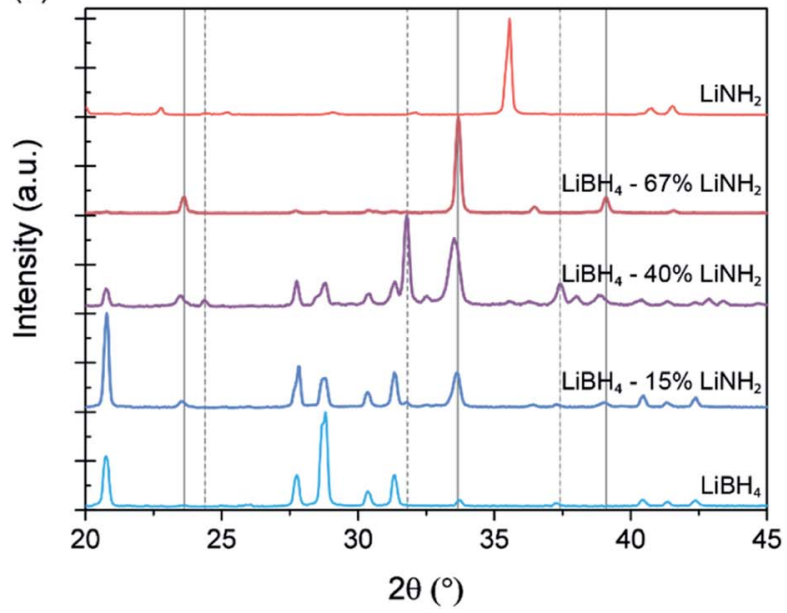

(b)

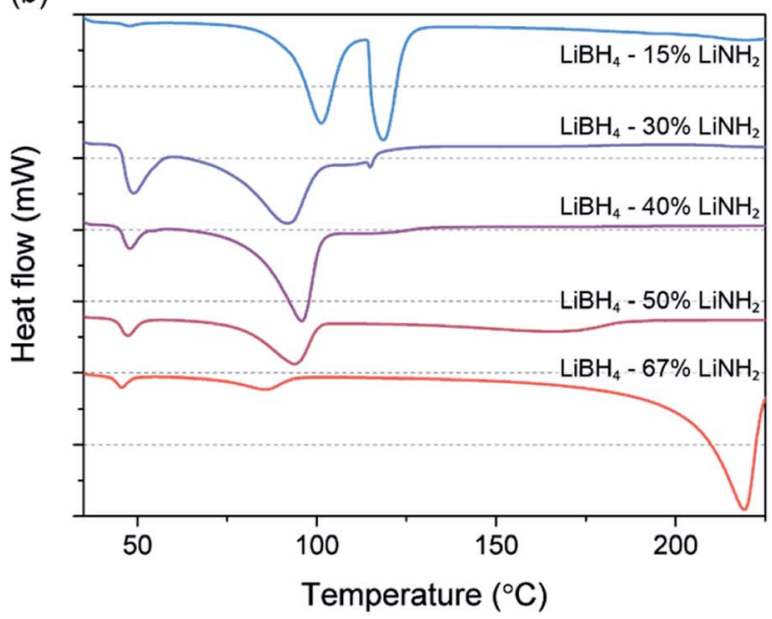

Fig. 1 (a) XRD powder patterns and (b) DSC graphs of $\mathrm{LiBH}_{4}-\mathrm{LiNH}_{2}$ phase mixtures containing between 15 and $67 \mathrm{~mol}^{2} \mathrm{LiNH}$. For comparison, XRD patterns of pure $\mathrm{LiBH}_{4}$ and $\mathrm{LiNH}_{2}$ are included. Reflections related to $\mathrm{Li}_{2}\left(\mathrm{BH}_{4}\right)\left(\mathrm{NH}_{2}\right)$ and $\mathrm{Li}_{4}\left(\mathrm{BH}_{4}\right)\left(\mathrm{NH}_{2}\right)_{3}$ are indicated by the dashed and straight lines, respectively. 
as demonstrated by XRD is further corroborated with differential scanning calorimetry (DSC) and diffuse reflectance infrared Fourier transform spectroscopy (DRIFTS) as shown in Fig. 1b and $\mathrm{S} 4, \dagger$ respectively.

With differential scanning calorimetry, different $\mathrm{LiBH}_{4}$ $\mathrm{LiNH}_{2}$ phases can be distinguished by their specific phase transition (melting) temperature. In Fig. 1b the DSC curves of $\mathrm{LiBH}_{4}-\mathrm{LiNH}_{2}$ phase mixtures containing 15 to $67 \mathrm{~mol} \% \mathrm{LiNH}_{2}$ are shown. The DSC results reveal that up to three different $\mathrm{LiBH}_{4}-\mathrm{LiNH}_{2}$ phases are formed in the prepared $\mathrm{LiBH}_{4}-\mathrm{LiNH}_{2}$ mixtures. For compositions with $30 \mathrm{~mol} \% \mathrm{LiNH}_{2}$ or less, the presence of unreacted $\mathrm{LiBH}_{4}$ is reflected by an endothermic peak around $110{ }^{\circ} \mathrm{C}$ due to the phase transition from orthorhombic to hexagonal $\mathrm{LiBH}_{4}$. Melting of the $\gamma$ - and $\beta$-phase in the $\mathrm{LiBH}_{4}-\mathrm{LiNH}_{2}$ mixtures is revealed by endothermic peaks at $45{ }^{\circ} \mathrm{C}$ and $90-110{ }^{\circ} \mathrm{C}$, respectively. Notably, for compositions containing $40 \mathrm{~mol} \% \mathrm{LiNH}_{2}$ or more, the presence of $\mathrm{LiBH}_{4}$ is no longer observed, while a third peak attributed to melting of the $\alpha$-phase is identified between $120{ }^{\circ} \mathrm{C}$ and $220{ }^{\circ} \mathrm{C}$. With increasing amount of $\mathrm{LiNH}_{2}$ the area of this peak increases, indicating that the amount of the $\alpha$-phase increases. The peak also shifts to higher temperatures, which can be ascribed to the formation of a more stable $\mathrm{LiBH}_{4}-\mathrm{LiNH}_{2}$ compound with increasing $\mathrm{LiNH}_{2}$ content. To summarize, in line with the results described by Meisner et al. both XRD and DSC reveal the formation of new $\mathrm{LiBH}_{4}-\mathrm{LiNH}_{2}$ phases. ${ }^{62}$ Note here that the composition and thereby the melting temperature of the prepared $\mathrm{LiBH}_{4}-\mathrm{LiNH}_{2}$ mixture depends on the molar fraction of $\mathrm{LiNH}_{2}$. The melting point of the $\mathrm{LiBH}_{4}-\mathrm{LiNH}_{2}$ mixture plays a key role in the preparation of nanoconfined $\mathrm{LiBH}_{4}-\mathrm{LiNH}_{2}$ through melt infiltration as will be discussed in the following section.

The effect of partial ionic substitution with $\mathrm{LiNH}_{2}$ on the conductivity of $\mathrm{LiBH}_{4}$ is analysed by recording the complex impedance of the $\mathrm{LiBH}_{4}-\mathrm{LiNH}_{2}$ mixtures over a range of temperatures. Previous studies have mainly focussed on the conductivity of $\mathrm{LiBH}_{4}-\mathrm{LiNH}_{2}$ with a high $\mathrm{LiNH}_{2}$ content, i.e. 50, 67 and $75 \mathrm{~mol} \% \mathrm{LiNH}_{2} \cdot{ }^{27,29}$ In this study, the conductivity is determined for $\mathrm{LiBH}_{4}-\mathrm{LiNH}_{2}$ mixtures containing 5 to $75 \mathrm{~mol} \%$ $\mathrm{LiNH}_{2}$. The conductivity data as derived from the complex impedance analysis are displayed in Fig. 2a. Overall, an improvement in conductivity compared to pure $\mathrm{LiBH}_{4}$ is seen for all $\mathrm{LiBH}_{4}-\mathrm{LiNH}_{2}$ mixtures. Generally, a sharp increase in conductivity with temperature is observed between $25{ }^{\circ} \mathrm{C}$ and $40{ }^{\circ} \mathrm{C}$ as was previously observed by Yan et al. for $\mathrm{Li}_{3}\left(\mathrm{BH}_{4}\right)$ $\left(\mathrm{NH}_{2}\right)_{2} \cdot{ }^{29}$ The increased conductivity is related to melting of the $\mathrm{LiBH}_{4}-\mathrm{LiNH}_{2} \gamma$-phase, as revealed by DSC in Fig. 1b. At temperatures above $40{ }^{\circ} \mathrm{C}$ the conductivity generally shows a negligible temperature dependence, suggesting a superionic conducting phase. To demonstrate the difference in conductivity between the different phase mixtures in this region, the conductivity at $50{ }^{\circ} \mathrm{C}$ for each $\mathrm{LiBH}_{4}-\mathrm{LiNH}_{2}$ composition is shown in Fig. 2b. In particular for $\mathrm{LiBH}_{4}-\mathrm{LiNH}_{2}$ containing 30 to $50 \mathrm{~mol} \% \mathrm{LiNH}_{2}$ a high conductivity is observed, reaching about $4 \times 10^{-4} \mathrm{~S} \mathrm{~cm}^{-1}$ at $50{ }^{\circ} \mathrm{C}$. Notably, in $\mathrm{LiBH}_{4}-\mathrm{LiNH}_{2}$ with a lower $\mathrm{LiNH}_{2}$ content (less than 30\%) unreacted $\mathrm{LiBH}_{4}$ is present, while materials with a higher $\mathrm{LiNH}_{2}$ content (above $50 \%$ predominantly contain the $\mathrm{LiBH}_{4}-\mathrm{LiNH}_{2} \alpha$-phase (Fig. 1b). It is apparent that the presence of unreacted $\mathrm{LiBH}_{4}$ - or $\alpha$-phase reduces the overall conductivity, in contrast to the $\mathrm{LiBH}_{4}-\mathrm{LiNH}_{2} \gamma$ - and $\beta$-phase that are beneficial for a higher conductivity. Consequently, an optimum in conductivity is achieved for $\mathrm{LiBH}_{4}-\mathrm{LiNH}_{2}$ containing 30 to $50 \mathrm{~mol} \% \mathrm{LiNH}_{2}$, lower than the $\mathrm{LiNH}_{2}$ content in the materials that were previously studied.

\section{Nanoconfinement of $\mathrm{LiBH}_{4}-\mathrm{LiNH}_{2}$ in mesoporous $\mathrm{SiO}_{2}$ scaffold}

The effect of nanoconfinement in mesoporous MCM-41 $\left(\mathrm{SiO}_{2}\right)$ on the structure and conductivity of $\mathrm{LiBH}_{4}-\mathrm{LiNH}_{2}$ is discussed specifically for the mixtures containing 30 to $50 \mathrm{~mol} \% \mathrm{LiNH}_{2}$, as these compositions had the highest conductivities. To start, we (a)

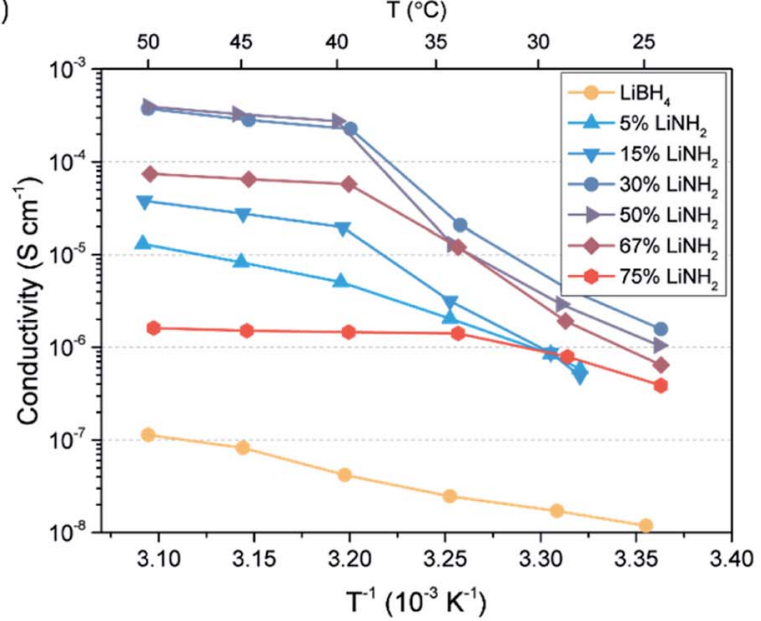

(b)

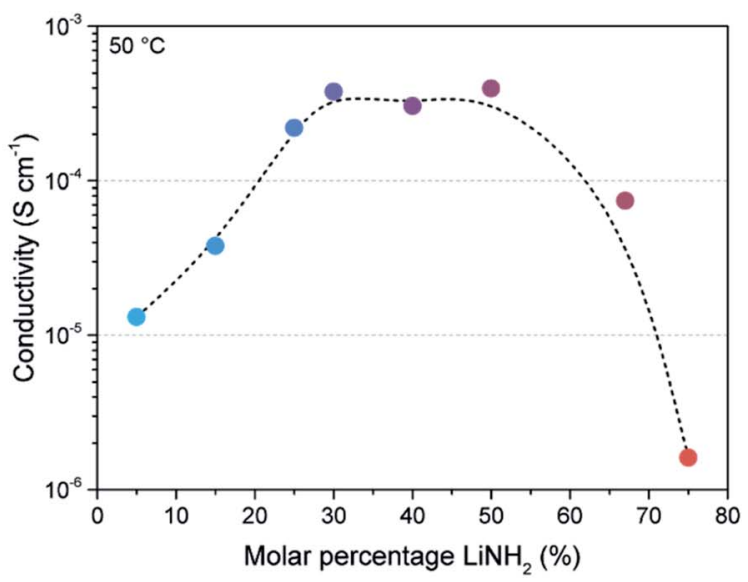

Fig. 2 (a) Arrhenius plots visualizing conductivity versus reciprocal temperature of $\mathrm{LiBH}_{4}-\mathrm{LiNH}_{2}$ solid electrolytes with 5 to 75 mol\% $\mathrm{LiNH} 2$ as well as pure $\mathrm{LiBH}_{4}$. (b) Conductivity dependence on $\mathrm{LiNH}_{2}$ content in the $\mathrm{LiBH}_{4}-\mathrm{LiNH}_{2}$ phase mixtures. The dashed line is added to guide the eye and has no physical meaning. 
(a)

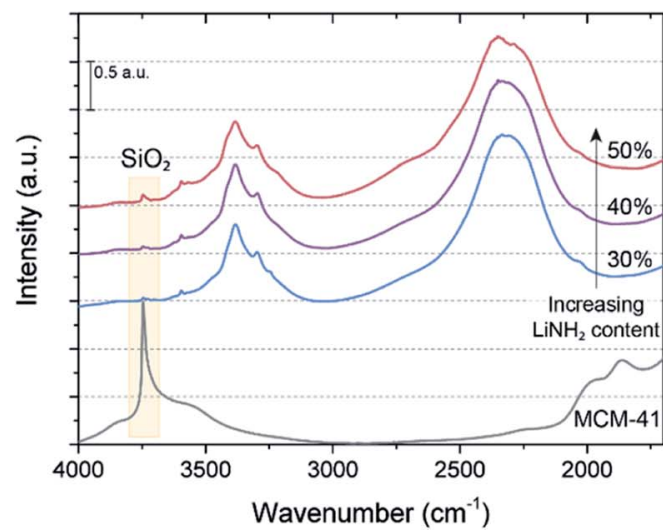

(b)

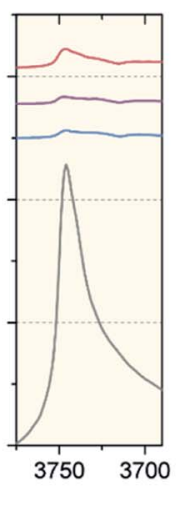

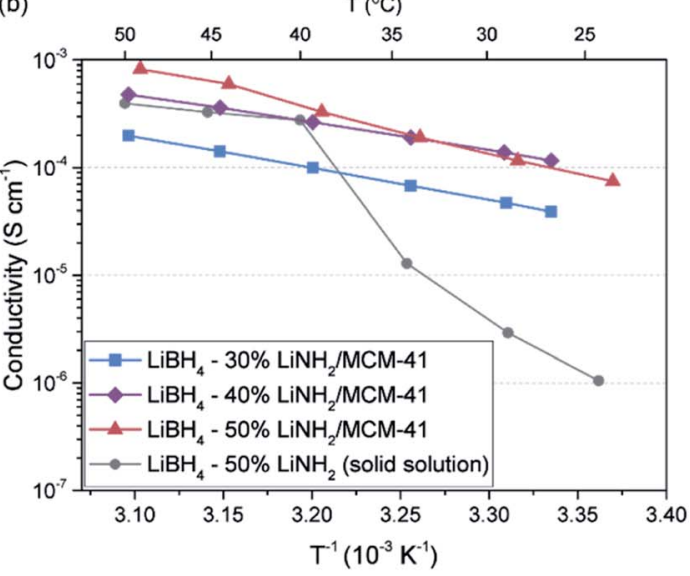

Fig. 3 (a) DRIFTS spectra of $\mathrm{LiBH}_{4}-\mathrm{LiNH}_{2} / \mathrm{SiO}_{2}$ nanocomposites. An enlargement is given of the region associated with hydroxyl stretching $\left(3800-3700 \mathrm{~cm}^{-1}\right)$. (b) Arrhenius plots visualizing conductivity versus reciprocal temperature of $\mathrm{LiBH}_{4}-\mathrm{LiNH}_{2}$ nanocomposites.

discuss the structural changes and effectiveness of the synthesis method, i.e. incorporation of the metal hydride in the pores of the mesoporous oxide, as observed by DRIFTS. In Fig. 3a the DRIFTS absorbance spectra of the prepared nanocomposites as well as MCM-41 are visualized. The spectra of the corresponding $\mathrm{LiBH}_{4}-\mathrm{LiNH}_{2}$ phase mixtures are provided in Fig. S4. $\dagger$ In the DRIFTS spectra three regions of interest are identified. First, macrocrystalline $\mathrm{LiBH}_{4}$ typically displays three characteristic bands between 2000 and $2800 \mathrm{~cm}^{-1}$, corresponding to the $\left[\mathrm{BH}_{4}{ }^{-}\right]$stretching vibrations. ${ }^{64}$ The nanocomposite spectra contain a broad band in this region. The broadening effect was observed in previous studies on nanoconfined $\mathrm{LiBH}_{4}$, and was attributed to increased rotational freedom of the $\left[\mathrm{BH}_{4}{ }^{-}\right]$anion due to the structural changes induced by nanoconfinement. ${ }^{43}$ Secondly, two sharp bands related to $[\mathrm{N}-\mathrm{H}]$ stretching vibrations of $\mathrm{LiNH}_{2}$ are typically present at 3260 and $3310 \mathrm{~cm}^{-1} \cdot{ }^{65} \mathrm{In}$ the nanocomposites spectra, these sharp peaks are no longer observed. Instead, a broad peak at a slightly higher wavenumber (3000-3500 $\left.\mathrm{cm}^{-1}\right)$ is seen. Similar to the observations on $\left[\mathrm{BH}_{4}{ }^{-}\right]$, the broadening effect indicates an increased rotational freedom of the $\left[\mathrm{NH}_{2}{ }^{-}\right]$anion caused by structural changes upon nanoconfinement. Likewise, the peak shift towards a higher wave number can be attributed to a change in the $\mathrm{Li}-\mathrm{N}-\mathrm{H}$ bonding due to interactions with the surface groups of the oxide scaffold, as reported for $\mathrm{LiBH}_{4}$ nanoconfined in $\mathrm{Al}_{2} \mathrm{O}_{3}$ and $\mathrm{SiO}_{2}$.

The last region of interest is ascribed to the hydroxyl stretching vibration of the $\mathrm{SiO}_{2}$ silanol groups appearing around $3746 \mathrm{~cm}^{-1} \cdot{ }^{66}$ Compared to the pure MCM-41 scaffold, this vibration almost completely disappears in nanoconfined $\mathrm{LiBH}_{4}-\mathrm{LiNH}_{2}$ with 30 to $50 \mathrm{~mol} \% \mathrm{LiNH}_{2}$. In previous studies it has been found that the silanol vibrations disappear when the pores of the scaffold are filled with an electrolyte salt, as the hydroxyl vibrations are supressed by interactions or reaction between the silanol groups and the confined electrolyte. ${ }^{\mathbf{4 3 , 4 8}}$ This is clearly also the case for nanoconfined $\mathrm{LiBH}_{4}-\mathrm{LiNH}_{2}$, implying that for the used compositions, the melt infiltration process results in the successful incorporation of $\mathrm{LiBH}_{4}-\mathrm{LiNH}_{2}$ in the oxide pores. Further evidence for the incorporation of $\mathrm{LiBH}_{4}-\mathrm{LiNH}_{2}$ into the oxide pores is provided by XRD and $\mathrm{N}_{2}$ physisorption (Fig. $\mathrm{S} 5 \dagger$ ). The XRD diffraction pattern for the nanoconfined $\mathrm{LiBH}_{4}-50 \% \mathrm{LiNH}_{2}$ shows a complete loss of crystallinity, as expected for nanoconfined materials, ${ }^{50}$ while with $\mathrm{N}_{2}$ physisorption a loss in pore volume with increasing amount of $\mathrm{LiBH}_{4}-\mathrm{LiNH}_{2}$ is observed, consistent with successful infiltration of the metal hydride in the pores of the mesoporous oxide. $^{48,50}$

The conductivity of the nanocomposites is shown in Fig. 3b. In general, ionic transport at temperatures below $40{ }^{\circ} \mathrm{C}$ increased by one to two orders of magnitude compared to the corresponding $\mathrm{LiBH}_{4}-\mathrm{LiNH}_{2}$ phase mixtures. Notably, the highest conductivity of $1 \times 10^{-4} \mathrm{~S} \mathrm{~cm}^{-1}$ at $30{ }^{\circ} \mathrm{C}$ is achieved for $\mathrm{LiBH}_{4}-40 \% \mathrm{LiNH}_{2} / \mathrm{MCM}-41$, close to ionic conductivities observed for state of the art solid electrolytes, such as thiophosphates. ${ }^{6,7}$ To compare, the conductivity is 40 times higher than the initial (non-confined) $\mathrm{LiBH}_{4}-\mathrm{LiNH}_{2}, 5$ times higher than nanoconfined $\mathrm{LiBH}_{4}$ and over 4 orders of magnitude higher than nanoconfined $\mathrm{LiNH}_{2}$ (Fig. S6†). Furthermore, over the recorded temperature range, no phase change-induced conductivity increase is identified, in contrast to non-confined $\mathrm{LiBH}_{4}-\mathrm{LiNH}_{2}$ that revealed a structural phase change leading to a highly conducting phase above $40{ }^{\circ} \mathrm{C}$. This suggests that the observed conductivity enhancement might originate from another phenomenon, such as stabilization of the high conductivity $\mathrm{LiBH}_{4}-\mathrm{LiNH}_{2}$ phase at lower temperatures through nanoconfinement, in addition to the formation of a conductive interface layer as is the case for nanoconfined $\mathrm{LiBH}_{4}$.

The activation energy for long-range ion transport in the nanocomposites was derived from the slope in the Arrhenius plots. A summary of the activation energies is shown in Table 1. For the $\mathrm{LiBH}_{4}-\mathrm{LiNH}_{2} / \mathrm{MCM}-41$ nanocomposites the activation energies vary from $0.51( \pm 0.01) \mathrm{eV}$ to $0.80( \pm 0.03) \mathrm{eV}$, whereas the activation energy of the low temperature $\mathrm{LiBH}_{4}-\mathrm{LiNH}_{2}$ phase (between 25 and $35{ }^{\circ} \mathrm{C}$ ) is $2.0( \pm 0.2) \mathrm{eV}$. Hence, in agreement with the enhancement in conductivity, the activation energy for ion transport has decreased upon nanoconfinement of $\mathrm{LiBH}_{4}-\mathrm{LiNH}_{2}$. Note that the activation energy of the high temperature (HT) $\mathrm{LiBH}_{4}-\mathrm{LiNH}_{2}$ phase (above $40{ }^{\circ} \mathrm{C}$ ) is even 
Table 1 Activation energies $\left(E_{\mathrm{a}}\right)$ and pre-factors $(\ln (A))$ derived for $\mathrm{LiBH}_{4}-\mathrm{LiNH}_{2} / \mathrm{MCM}-41$ nanocomposites using Arrhenius laws to approximate the temperature dependence between $25^{\circ} \mathrm{C}$ and $50^{\circ} \mathrm{C}$

\begin{tabular}{llr}
\hline Sample & $E_{\mathrm{a}}(\mathrm{eV})$ & Pre-factor ln $(A)$ \\
\hline $\mathrm{LiBH}_{4}-50 \% \mathrm{LiNH}_{2}\left(\mathrm{LT}^{a} / \mathrm{HT}^{b}\right)$ & $2.0( \pm 0.2) / 0.32( \pm 0.02)$ & $3.6( \pm 0.6) / 64( \pm 6)$ \\
$\mathrm{LiBH}_{4}-30 \% \mathrm{LiNH}_{2} / \mathrm{MCM}-41$ & $0.59( \pm 0.01)$ & $12.6( \pm 0.1)$ \\
$\mathrm{LiBH}_{4}-40 \% \mathrm{LiNH}_{2} / \mathrm{MCM}-41$ & $0.51( \pm 0.01)$ & $10.8( \pm 0.2)$ \\
$\mathrm{LiBH}_{4}-50 \% \mathrm{LiNH} / \mathrm{MCM}-41$ & $0.80( \pm 0.03)$ & $21.9( \pm 0.9)$ \\
${ }^{a} E_{\mathrm{a}}$ low temperature $(\mathrm{LT})$ phase determined from $25{ }^{\circ} \mathrm{C}$ to $35{ }^{\circ} \mathrm{C} .{ }^{b} E_{\mathrm{a}}$ high temperature $(\mathrm{HT})$ phase determined from $40{ }^{\circ} \mathrm{C}$ to $50{ }^{\circ} \mathrm{C}$.
\end{tabular}

lower, consistent with a molten phase in which the $\mathrm{Li}^{+}$-ions can move easily. This molten phase could be related to melting of $\mathrm{LiBH}_{4}-\mathrm{LiNH}_{2} \gamma$-phase or the liquid phase $\mathrm{LiBH}_{4} \cdot\left(\mathrm{NH}_{3}\right)_{0.5}$ as described in a recent work by Yan et al. ${ }^{63}$ The variation in the activation energy for the different nanocomposites is due to the differences in composition of the nanoconfined $\mathrm{LiBH}_{4}-\mathrm{LiNH}_{2}$. As explained in the previous section, in each $\mathrm{LiBH}_{4}-\mathrm{LiNH}_{2}$ mixture different phase(s) are present, which has a consequence for the Li-ion dynamics within the materials. The higher activation energy of $\mathrm{LiBH}_{4}-30 \% \mathrm{LiNH}_{2} / \mathrm{MCM}-41$ and $\mathrm{LiBH}_{4}-50 \%$ $\mathrm{LiNH}_{2} / \mathrm{MCM}-41$ compared to $\mathrm{LiBH}_{4}-40 \% \mathrm{LiNH}_{2} / \mathrm{MCM}-41$ can be explained by the presence of unreacted $\mathrm{LiBH}_{4}$ and $\alpha$-phase $\mathrm{LiBH}_{4}-\mathrm{LiNH}_{2}$ in the respective $\mathrm{LiBH}_{4}-\mathrm{LiNH}_{2}$ phase mixtures.

\section{Effects of the scaffold properties on nanocomposite conductivity}

It is clear that the conductivities of the $\mathrm{LiBH}_{4}-\mathrm{LiNH}_{2}$ phase mixtures are significantly enhanced by nanoconfinement in the pores of mesoporous silica (MCM-41). For pure $\mathrm{LiBH}_{4}$, the enhancement in conductivity upon nanoconfinement in a mesoporous oxide has been attributed to the interactions between surface groups of the oxide and the confined metal hydride, which leads to the formation of a space-charge region or highly defected layer at the $\mathrm{LiBH}_{4} /$ oxide interface..$^{39,43,51}$ In this case, the chemical nature of the scaffold, especially the surface chemistry, is crucial for the interface effects, and thereby the conductivity of the $\mathrm{LiBH}_{4}$ /oxide nanocomposite. Alternatively, it is also known that nanoconfinement can lead to a reduction in phase transition temperature, which can profoundly influence the properties of nanoconfined complex hydrides. This effect depends strongly on the pore structure of the mesoporous oxides, as described by the Gibbs-Thomson equation which shows an inverse relationship between the phase transition temperature of a confined material and the size of the confining pore. ${ }^{67}$ Hence, it is expected that the properties of the scaffold are important in determining the effect of confinement, and thereby the conductivity of the metal hydride nanocomposites.

The impact of the chemical nature of the scaffold surface as well as the porosity on the nanocomposite conductivity was studied by preparing nanocomposites using $\mathrm{SBA}-15\left(\mathrm{SiO}_{2}\right)$ scaffolds with varying surface chemistry and porosity. Similar to MCM-41, SBA-15 is a hexagonally shaped mesoporous silica. The reason for using SBA-15 in this study is that unlike MCM41 , the pore diameter and pore volume of SBA-15 can be readily tuned by changing the condensation temperature $\left(T_{\mathrm{c}}\right)$, while particle size, and thereby pore length, as well as surface area are not (significantly) affected..$^{57,68,69}$ Moreover, using surface grafting techniques, such as surface alumination, the surface chemistry of SBA-15 can be altered. Hence, SBA-15 is a good model system to study the impact of both the physical and chemical properties of scaffolds on the conductivity of the nanocomposites.

Surface chemistry effects. In the previous section, it was observed that the surface groups of the scaffold interact with
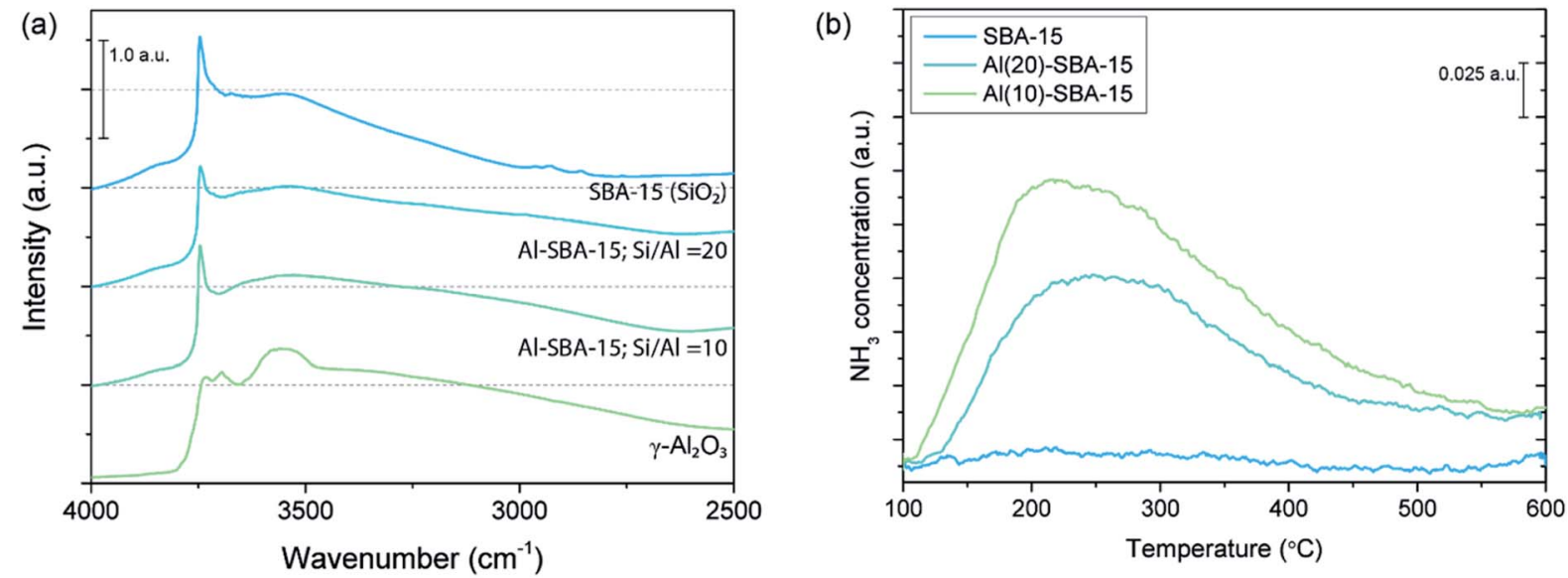

Fig. 4 (a) DRIFTS spectra of SBA-15, Al-SBA-15 and $\gamma-\mathrm{Al}_{2} \mathrm{O}_{3}$, displaying the region related to hydroxyl stretching vibrations. (b) $\mathrm{NH}_{3}-\mathrm{TPD}$ of unmodified SBA-15 and aluminated SBA-15. 
nanoconfined $\mathrm{LiBH}_{4}-\mathrm{LiNH}_{2}$ (Fig. 3), suggesting that interface interactions could impact nanocomposite conductivity. This was investigated in more detail using nanocomposites of $\mathrm{LiBH}_{4}-\mathrm{LiNH}_{2}$ nanoconfined in SBA-15 $\left(\mathrm{SiO}_{2}\right)$ scaffolds with varying surface chemistry.

For an accurate analysis of the role of interfacial interactions, the influence of other scaffold properties, such as morphology and porosity, should be minimal. For this purpose, aluminated (Al)-SBA-15, with $\mathrm{Si} / \mathrm{Al}=20$ and 10, was prepared through surface alumination of conventional SBA-15. Upon alumination, the amount and chemical nature of surface hydroxyl groups is modified, which can be (qualitatively) observed in the DRIFTS spectra of the oxides provided in Fig. 4a. Here, the difference in vibrational energy of the surface hydroxyl groups on SBA-15, Al-SBA-15 and $\gamma-\mathrm{Al}_{2} \mathrm{O}_{3}$ is visualized. In general, the hydroxyl groups of aluminated SBA- 15 and $\gamma-\mathrm{Al}_{2} \mathrm{O}_{3}$ exhibit a larger variety in vibrational energy compared to unmodified SBA-15. This is related to the difference in the chemical nature of the surface hydroxyl groups on the oxides. Typically, $\mathrm{SiO}_{2}$ (SBA-15) contains only weak Brønsted acidic silanol groups, while $\mathrm{Al}_{2} \mathrm{O}_{3}$, and consequently Al-SBA-15, contain Brønsted acidic and Brønsted basic sites. ${ }^{58,70}$

Using $\mathrm{NH}_{3}$-TPD, the number of acid sites present in unmodified SBA- 15 and aluminated SBA- 15 that are sufficiently strong to interact with $\mathrm{NH}_{3}$ was determined. In Fig. $4 \mathrm{~b}$, the $\mathrm{NH}_{3}$ TPD measurements of unmodified SBA-15, Al(20)-SBA-15 and $\mathrm{Al}(10)$-SBA-15 are depicted. It was found that the amount of acid sites increases from $18.5 \mu \mathrm{mol} \mathrm{g}^{-1}$ in the unmodified scaffold to $204.1 \mu \mathrm{mol} \mathrm{g}^{-1}$ in $\mathrm{Al}(20)-\mathrm{SBA}-15$ and $295.5 \mu \mathrm{mol} \mathrm{g}^{-1}$ in $\mathrm{Al}(10)-$ SBA-15. To compare, $\gamma-\mathrm{Al}_{2} \mathrm{O}_{3}$ contains $624.0 \mu \mathrm{mol} \mathrm{g}{ }^{-1}$ acid sites. Therefore, both DRIFTS and $\mathrm{NH}_{3}$-TPD analysis confirm that the surface of SBA-15 was successfully modified through alumination. Moreover, the porosity of the scaffolds was analysed with $\mathrm{N}_{2}$ physisorption. The obtained information on porosity of the scaffolds is summarized in Table S2. $\dagger$ Compared to the unmodified SBA-15, surface alumination results in a minor decrease in pore volume from 0.99 to $0.92 \mathrm{~cm}^{3} \mathrm{~g}^{-1}$ for both aluminated scaffolds. Altogether, the prepared aluminated SBA-15 scaffolds are a useful model system with varying surface chemistry and without significant differences in pore size, pore volume or surface area.

The aluminated SBA-15 scaffolds were used to prepare nanoconfined $\mathrm{LiBH}_{4}-\mathrm{LiNH}_{2}$. In Fig. 5 the conductivities of the $\mathrm{LiBH}_{4}-\mathrm{LiNH}_{2} /$ metal oxide nanocomposites prepared with SBA15, $\mathrm{Al}(20)-\mathrm{SBA}-15, \mathrm{Al}(10)-\mathrm{SBA}-15$ are shown. The room temperature conductivity of the prepared nanocomposites was larger than for non-confined $\mathrm{LiBH}_{4}-\mathrm{LiNH}_{2}$. Interestingly, the nanocomposite conductivity increased slightly from $2.0 \times$ $10^{-4} \mathrm{~S} \mathrm{~cm}^{-1}$ to $3.6 \times 10^{-4} \mathrm{~S} \mathrm{~cm}^{-1}$ with increasing surface alumination. It is not likely that this difference is related to the minor difference in scaffold porosity. This observation therefore suggests that the difference in conductivity results from the change in the surface chemistry arising from alumination.

Further insight into the effect of surface alumination is provided by analysis of the activation energy for ionic transport. For $\mathrm{LiBH}_{4}-\mathrm{LiNH}_{2} / \mathrm{SBA}-15$ nanocomposites an activation energy of $0.68( \pm 0.01) \mathrm{eV}$ is found, which is similar to the values

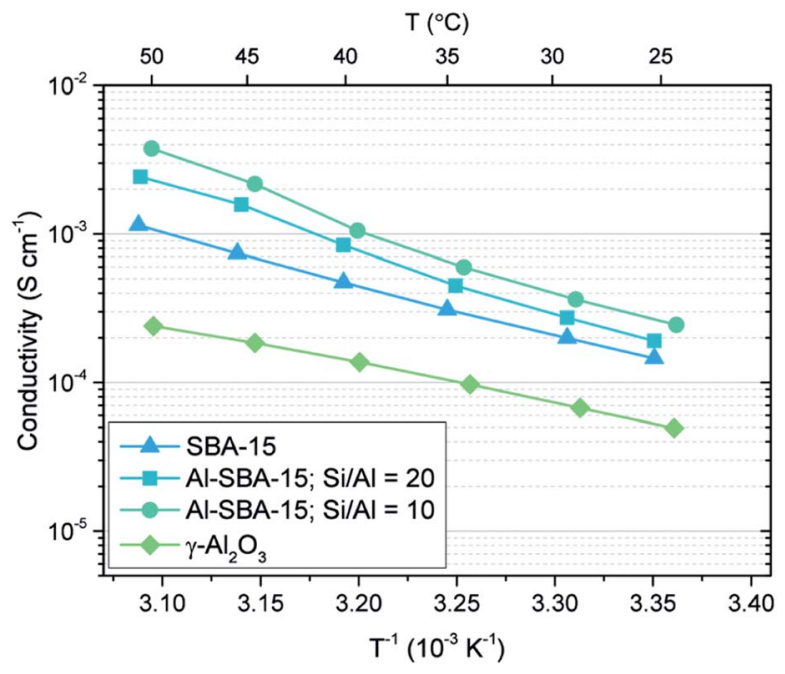

Fig. 5 Arrhenius plots of conductivity versus reciprocal temperature of $\mathrm{LiBH}_{4}-\mathrm{LiNH}_{2}$ nanoconfined in $\gamma-\mathrm{Al}_{2} \mathrm{O}_{3}, \mathrm{SBA}-15$ and aluminated SBA-15.

observed for the MCM-41-based nanocomposites. Surprisingly, the activation energy increases significantly in nanocomposites prepared with aluminated SBA-15 to $0.86( \pm 0.03) \mathrm{eV}(\mathrm{Si} / \mathrm{Al}=20)$ and $0.90( \pm 0.04) \mathrm{eV}(\mathrm{Si} / \mathrm{Al}=10)$. Here, a change in activation energy might be caused by the difference in surface chemistry through alumination, which influences the interactions between the scaffold surface and the nanoconfined metal hydride. This is another strong indication that the surface chemistry influences ion mobility in the nanocomposites.

The increase in conductivity with increasing surface alumination could be caused by two surface chemistry properties. Firstly, previous studies on $\mathrm{LiBH}_{4}$ nanoconfined in mesoporous $\mathrm{SiO}_{2}$ demonstrated that the ionic conductivity is strongly influenced by the density of the surface silanol groups. Specifically, a higher density of surface silanol groups is associated with a larger conductivity enhancement. ${ }^{43}$ Since alumina generally contains about 10 hydroxyl groups per $\mathrm{nm}^{2}$ while silica only contains 4 to 5.5 groups per $\mathrm{nm}^{2},{ }^{70}$ it is expected that aluminated SBA-15 contains more surface hydroxyl groups than unmodified SBA-15, which could explain an increase in conductivity. Additionally, as illustrated with $\mathrm{NH}_{3}$-TPD, the chemical nature of surface hydroxyl groups in unmodified SBA15 and aluminated SBA- 15 varies significantly. While $\mathrm{SiO}_{2}$ (SBA15) contains weakly acidic hydroxyl groups, aluminated SBA-15 contains surface groups with either acidic or basic character, similar to $\gamma-\mathrm{Al}_{2} \mathrm{O}_{3}$. The difference in chemical nature of the surface groups will likely alter the nature and strength of the interfacial interactions with nanoconfined $\mathrm{LiBH}_{4}-\mathrm{LiNH}_{2}$, thereby changing conductivity. With this in mind, it becomes clear that the surface chemistry of the scaffold can have a huge impact on the conductivity of $\mathrm{LiBH}_{4}-\mathrm{LiNH}_{2} /$ metal oxide nanocomposites.

Surprisingly, the conductivity of the nanocomposite prepared with pure alumina $\left(\mathrm{LiBH}_{4}-\mathrm{LiNH}_{2} / \gamma-\mathrm{Al}_{2} \mathrm{O}_{3}\right)$ was much lower than for the nanocomposites prepared with SBA-15 and 
Al-SBA-15. In fact, at room temperature the conductivity was almost 10 times lower than that of $\mathrm{LiBH}_{4}-\mathrm{LiNH}_{2} / \mathrm{Al}(10)-\mathrm{SBA}-15$ $\left(6.7 \times 10^{-5} \mathrm{~S} \mathrm{~cm}^{-1}\right)$, despite the fact that the amount of surface acid sites present in $\gamma-\mathrm{Al}_{2} \mathrm{O}_{3}$ is significantly higher (624.0 $\mu \mathrm{mol} \mathrm{g}^{-1}$ compared to $295.5 \mu \mathrm{mol} \mathrm{g}{ }^{-1}$ ). It is important to realize that the physical properties, especially the porosity, of $\gamma$ $\mathrm{Al}_{2} \mathrm{O}_{3}$ and aluminated SBA-15 differ substantially. For instance, the pore volume is $0.92 \mathrm{~cm}^{3} \mathrm{~g}^{-1}$ for Al-SBA-15 and $0.48 \mathrm{~cm}^{3} \mathrm{~g}^{-1}$ for $\gamma-\mathrm{Al}_{2} \mathrm{O}_{3}$, while Al-SBA-15 contains small uniform pores $(\varnothing=$ $6.6 \mathrm{~nm})$ and $\mathrm{Al}_{2} \mathrm{O}_{3}$ has a broad pore size distribution $(\varnothing=6.3-$ $11.1 \mathrm{~nm}$ ) (Table $\mathrm{S} 2 \dagger$ ). Hence, the difference in conductivity cannot be solely ascribed to the difference in surface chemistry. Instead, it seems that other factors, especially the physical properties (surface area, pore structure and pore volume) of the scaffold, might play a crucial role in the enhancement of nanocomposite conductivity as well.

Porosity effects. The impact of scaffold porosity was studied by preparing nanocomposites using $\mathrm{SBA}-15\left(\mathrm{SiO}_{2}\right)$ scaffolds with varying pore sizes, tuned by varying the condensation temperature between $45{ }^{\circ} \mathrm{C}$ and $120{ }^{\circ} \mathrm{C} . .^{57,68,69}$ Note that, this approach also leads to changes in the specific surface area and pore volume of the scaffold. A summary of the properties of the SBA-15 as derived from the $\mathrm{N}_{2}$ physisorption measurements is provided in Table 2 and the pore size distribution of the synthesized SBA-15 scaffolds is shown in Fig. 6. The scaffold pore volume increased with increasing condensation temperature from $0.54 \mathrm{~cm}^{3} \mathrm{~g}^{-1}$ for SBA-15 prepared at $45{ }^{\circ} \mathrm{C}$, up to 1.06 and $1.00 \mathrm{~cm}^{3} \mathrm{~g}^{-1}$ for SBA-15 prepared at 100 and $120{ }^{\circ} \mathrm{C}$, respectively. Likewise, the pore diameter increased from 5.1 to $8.3 \mathrm{~nm}$ when increasing the condensation temperature from $45{ }^{\circ} \mathrm{C}$ to $100{ }^{\circ} \mathrm{C}$. Increasing the condensation temperature further from $100{ }^{\circ} \mathrm{C}$ to $120{ }^{\circ} \mathrm{C}$ led to a similar pore volume, but a decrease in the pore size to $6.9 \mathrm{~nm}$. The surface area varied between 609.9 and $855.8 \mathrm{~m}^{2} \mathrm{~g}^{-1}$, however no obvious correlation between condensation temperature and surface area was observed. Thus, by varying condensation temperature, several mesoporous SBA-15 $\left(\mathrm{SiO}_{2}\right)$ scaffolds with large differences in pore structure were synthesized.

The SBA-15 scaffolds were used to prepare nanoconfined $\mathrm{LiBH}_{4}-50 \% \mathrm{LiNH}_{2}$, as well as nanoconfined $\mathrm{LiBH}_{4}$ for comparison. The conductivity of the resulting nanocomposites is displayed in Fig. 7a and b. It is evident that the conductivity of the $\mathrm{LiBH}_{4}-\mathrm{LiNH}_{2} / \mathrm{SBA}-15$ nanocomposites differs significantly. Notably, at $30{ }^{\circ} \mathrm{C}$ the nanocomposites based on SBA-15

Table 2 Physical properties of SBA-15 scaffolds synthesized with varying condensation temperature as determined by $\mathrm{N}_{2}$ physisorption

\begin{tabular}{lll}
\hline$T_{\text {condensation }}$ SBA-15 & $\begin{array}{l}\text { Pore volume } \\
\left(\mathrm{cm}^{3} \mathrm{~g}^{-1}\right)\end{array}$ & $\begin{array}{l}\text { BET surface } \\
\text { area }\left(\mathrm{m}^{2} \mathrm{~g}^{-1}\right)\end{array}$ \\
\hline $45{ }^{\circ} \mathrm{C}$ & 0.54 & 609.9 \\
$60{ }^{\circ} \mathrm{C}$ & 0.51 & 610.5 \\
$75{ }^{\circ} \mathrm{C}$ & 0.74 & 834.1 \\
$90^{\circ} \mathrm{C}$ & 0.71 & 720.9 \\
$100{ }^{\circ} \mathrm{C}$ & 1.06 & 805.1 \\
$120{ }^{\circ} \mathrm{C}$ & 1.00 & 628.7
\end{tabular}

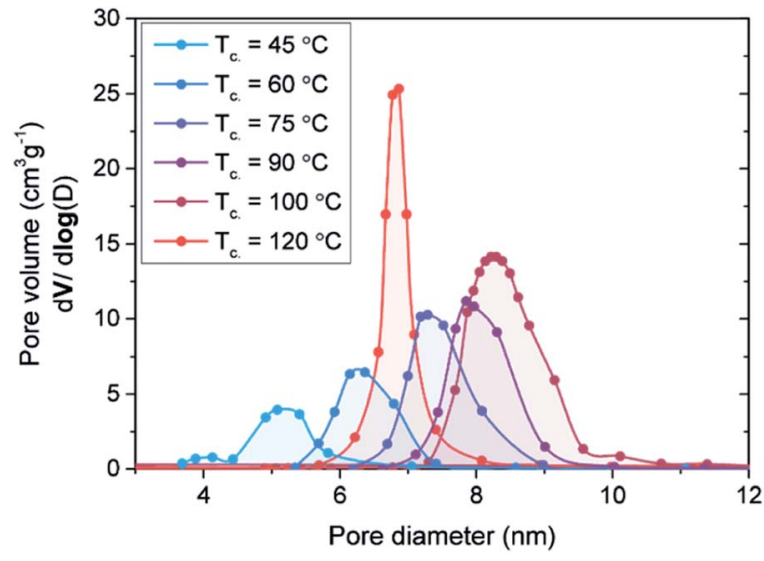

Fig. 6 Pore volume versus pore diameter as determined with $\mathrm{BJH}$ analysis of SBA-15 scaffolds synthesized with condensation temperatures varying from $45^{\circ} \mathrm{C}$ to $120^{\circ} \mathrm{C}$.

synthesized with $T_{\mathrm{c}}=60{ }^{\circ} \mathrm{C}$ and $T_{\mathrm{c}}=120{ }^{\circ} \mathrm{C}$ exhibit a difference of over three orders of magnitude in conductivity, from 3.6 $\times 10^{-7} \mathrm{~S} \mathrm{~cm}^{-1}$ to $5.1 \times 10^{-4} \mathrm{~S} \mathrm{~cm}^{-1}$, respectively. In contrast, $\mathrm{LiBH}_{4}$ /oxide nanocomposites prepared with these SBA-15 scaffolds display only a minor difference in conductivity, as the conductivity only differs by a factor of 4 when the nanocomposites are prepared with SBA-15 synthesized with $T_{\mathrm{c}}=$ $90{ }^{\circ} \mathrm{C}\left(6.9 \times 10^{-6} \mathrm{~S} \mathrm{~cm}^{-1}\right)$ and $T_{\mathrm{c}}=120^{\circ} \mathrm{C}\left(2.5 \times 10^{-5} \mathrm{~S} \mathrm{~cm}^{-1}\right)$.

It is important to realize that pellet porosity (void fraction) can be different for the different nanocomposites and thereby influence the conductivity. However, differences in void fractions are not expected to play a dominant role here, because $\mathrm{LiBH}_{4}-\mathrm{LiNH}_{2} /$ oxide and $\mathrm{LiBH}_{4} /$ oxide nanocomposites are both soft materials that likely exhibit a similar pellet porosity when compressed with the same force (as in this study). Also, comparing the dependence of their conductivity to the scaffold pore volume illustrates that the void fraction is not the determinant factor for the increase in conductivity of $\mathrm{LiBH}_{4}-\mathrm{LiNH}_{2}$ / oxide nanocomposites with increasing scaffold pore volume.

Interestingly, while a large difference in conductivity is observed for the $\mathrm{LiBH}_{4}-\mathrm{LiNH}_{2}$ nanoconfined in the different SBA-15 scaffolds, the activation energy for ion transport remains generally the same. For example, an activation energy of $0.75( \pm 0.03) \mathrm{eV}$ and $0.72( \pm 0.02) \mathrm{eV}$ are found for nanocomposites prepared with the scaffolds synthesized at $60{ }^{\circ} \mathrm{C}$ and $120^{\circ} \mathrm{C}$, respectively. This indicates that the intrinsic conduction mechanism is similar in all $\mathrm{LiBH}_{4}-\mathrm{LiNH}_{2} / \mathrm{SBA}-15$ nanocomposites, and that it is instead the density of charge carriers that influences the conductivity.

Even though it is obvious that scaffold porosity influences the nanocomposite conductivity, it is not easy to pinpoint which physical property, e.g. pore volume, surface area or pore diameter, dictates the overall conductivity. Variation in the SBA-15 condensation temperature affects each structural parameter, hence a detailed analysis is performed in which the conductivity is separately correlated to pore diameter, surface area and pore volume (Fig. S7†). Surprisingly, no clear trend was established between the conductivity of the nanocomposites and either the 

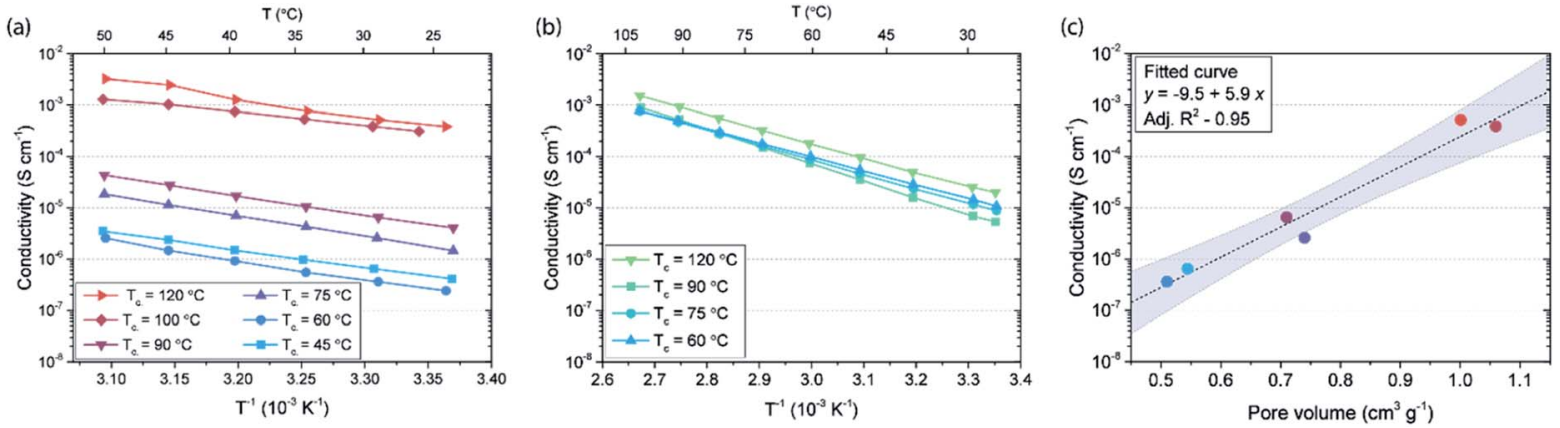

Fig. 7 Arrhenius plots showing conductivity versus reciprocal temperature of (a) $\mathrm{LiBH}_{4}-\mathrm{LiNH}_{2} / \mathrm{metal}$ oxide nanocomposites and (b) $\mathrm{LiBH} / \mathrm{metal}$ oxide nanocomposites prepared with the synthesized SBA-15 scaffolds. (c) Correlation between nanocomposite conductivity and pore volume of the applied SBA-15 scaffold, including the linear fit $(y=-9.5+5.9 x)$ and $95 \%$ confidence interval.

pore diameter or the surface area of the SBA-15. In fact, a clear correlation was only observed with the pore volume of the scaffold (Fig. 7c). From a general linear fit $(y=a+b x)$ on the $\log$-linear scale, the relation $\log (\sigma)=-9.5+5.9 V_{\text {pore }}$ is derived, showing a clear dependence of the conductivity to the scaffold pore volume. The main dependence of the conductivity on pore volume is unexpected, as in the previous section it was shown that interface interactions contribute to an enhance conductivity in nanoconfined anion-substituted metal hydrides.

The strong correlation between conductivity and pore volume strongly suggests that the conductivity enhancement in $\mathrm{LiBH}_{4}-\mathrm{LiNH}_{2} /$ metal oxide nanocomposites is mostly a result of stabilization of a highly conductive HT phase at room temperature in the scaffold pores. Note that this is distinctly different for $\mathrm{LiBH}_{4} /$ metal oxide nanocomposites, in which the conductivity enhancement is ascribed to the formation of a conductive interface layer. This is also in accord with the EIS results that indicate the absence of phase transitions over the temperature range between $25{ }^{\circ} \mathrm{C}$ and $50{ }^{\circ} \mathrm{C}$. A large pore volume is indeed expected to be beneficial for conductivity enhancement by phase stabilization. As explained in the experimental section, each nanocomposite contains an amount of $\mathrm{LiBH}_{4}-\mathrm{LiNH}_{2}$ that is equal to $130 \%$ of the scaffold pore volume. Consequently, a higher pore volume results in a larger weight and volume fraction of the highly conducting phase (nanoconfined $\mathrm{LiBH}_{4}{ }^{-}$ $\mathrm{LiNH}_{2}$ ) compared to the weight fraction of insulating $\mathrm{SiO}_{2}$ scaffold. For instance, the nanocomposite based on SBA-15 synthesized with $T_{\mathrm{c}}=60{ }^{\circ} \mathrm{C}$ contains $36.4 \mathrm{wt} \% \mathrm{LiBH}_{4}-\mathrm{LiNH}_{2}$ and $63.6 \mathrm{wt} \% \mathrm{SiO}_{2}$, while the nanocomposite based on SBA-15 synthesized with $T_{\mathrm{c}}=120^{\circ} \mathrm{C}$ consists for $52.8 \mathrm{wt} \%$ of $\mathrm{LiBH}_{4}{ }^{-}$ $\mathrm{LiH}_{2}$ and $47.2 \mathrm{wt} \%$ of $\mathrm{SiO}_{2}$. The higher weight fraction of phase stabilized $\mathrm{LiBH}_{4}-\mathrm{LiNH}_{2}$ compared to the fraction of insulating $\mathrm{SiO}_{2}$ leads to greater improvement in conductivity, hence, a high scaffold pore volume is beneficial for the nanocomposite conductivity.

This is in contrast to the case where the improved conductivity would be dictated by interface effects, as observed in nanoconfined $\mathrm{LiBH}_{4}$. In Fig. $7 \mathrm{~b}$ and $\mathrm{S} \uparrow$ it can be observed that the conductivity of $\mathrm{LiBH}_{4} /$ oxide nanocomposites does not depend on the weight fraction of $\mathrm{LiBH}_{4}$, and correspondingly, the scaffold pore volume. The absence of this correlation is in line with previous studies indicating that not the stabilization of the HT hexagonal $\mathrm{LiBH}_{4}$ phase, but rather a reaction or interaction at the interface with the oxide is responsible for the high conductivity of nanoconfined $\mathrm{LiBH}_{4}$. Hence, a high surface area and/or a high density of the reactive surface groups would give rise to an increase in scaffold-metal hydride interface interactions. The correlations between conductivity and both pore diameter and BET surface area (Fig. S7 $\dagger$ ) illustrate that this is not the case for nanoconfined $\mathrm{LiBH}_{4}-\mathrm{LiNH}_{2}$.

It is clear that within the range of the pore sizes (5.1-8.3 nm) studied here, the nanocomposites conductivity is mainly influenced by the scaffold pore volume, which determines the amount of the electrolyte that is nanoconfined per gram of mesoporous metal oxide. However, note that although no correlation exists between the conductivity and pore diameter (Fig. S7 $\dagger$ ), a pore diameter considerably larger than $8.3 \mathrm{~nm}$ will surely have a profound impact on the nanocomposite conductivity. According to the Gibbs-Thomson relation, the depression of the phase transition temperature of a confined material is inversely proportional to the pore size of the scaffold. Hence, stabilization of the high temperature $\mathrm{LiBH}_{4}-\mathrm{LiNH}_{2}$ phase at room temperature will only occur in nanopores that are small enough to induce a sufficient decrease in the phase transition temperature. Therefore, we can conclude that when conductivity enhancement originates from conductive phase stabilization, scaffolds with high pore volume and small pores are beneficial, while for conductivity enhancement mainly driven by interface interactions, scaffolds with high surface area are essential.

\section{Conclusions}

The influence of scaffold properties on the conductivity of nanoconfined $\mathrm{LiNH}_{2}$-substituted $\mathrm{LiBH}_{4}$ was systematically investigated using metal oxides with different surface chemistry and physical properties. The study reveals that the chemical nature of the scaffold influences the $\mathrm{LiBH}_{4}-\mathrm{LiNH}_{2} /$ metal oxide conductivity, as is expected. A conductivity improvement of a factor of two is achieved by changing the surface chemistry of SBA-15 through alumination. Surprisingly, the main factor contributing to an enhanced conductivity in $\mathrm{LiBH}_{4}-\mathrm{LiNH}_{2} /$ 
metal oxide nanocomposites, is the pore volume of the scaffold. A difference of three orders of magnitude in conductivity (reaching $5 \times 10^{-4} \mathrm{~S} \mathrm{~cm}^{-1}$ at $30^{\circ} \mathrm{C}$ ) is observed by varying the scaffold pore volume from 0.51 to $1.00 \mathrm{~cm}^{3} \mathrm{~g}^{-1}$.

Our work demonstrates that the origin of the conductivity enhancement in anion-substituted complex hydride-based solid electrolytes is quite different from other nanoconfined complex hydrides, e.g. $\mathrm{LiBH}_{4}$. Specifically, the conductivity can be enhanced not only via the formation of a highly conductive interface layer, but also via the stabilization of a high temperature (highly conductive) phase at room temperature. Thus, it is clear that the conductivity of metal hydride-based nanocomposite ion conductors is closely linked to the properties of scaffold materials.

While the enhancement of electrolyte conductivity is the focus of this study, other electrolyte properties, such as electrochemical stability and interface stability with electrode materials, are also essential for application. This constitutes the next milestone for the $\mathrm{LiBH}_{4}-\mathrm{LiNH}_{2}$ /oxide nanocomposites. However, the successful application of similar systems, i.e. $\mathrm{LiBH}_{4}-\mathrm{LiI} / \mathrm{Al}_{2} \mathrm{O}_{3}$ and non-confined $\mathrm{Li}\left(\mathrm{BH}_{4}\right)_{1-x}\left(\mathrm{NH}_{2}\right)_{x}$, demonstrates that metal hydride-based electrolytes are promising candidates for ASS batteries.

\section{Conflicts of interest}

There are no conflicts to declare.

\section{Acknowledgements}

We greatly appreciate funding from the NWO materials for sustainability (739.017.009) grant, as well as the NWO ECHO (712.015.005) grant. Furthermore, we thank Silvia Zanoni for physisorption measurements, Jan Willem de Rijk and Dennie Wezendonk for their technical support, as well as Matt Peerlings and Oscar Brandt Corstius for the synthesis of nanoconfined $\mathrm{LiNH}_{2}$ and MCM-41, respectively.

\section{Notes and references}

1 B. Dunn, H. Kamath and J. M. Tarascon, Science, 2011, 334, 928-935.

2 D. Larcher and J. M. Tarascon, Nat. Chem., 2015, 7, 19-29.

3 D. L. McCollum, W. Zhou, C. Bertram, H. S. De Boer, V. Bosetti, S. Busch, J. Després, L. Drouet, J. Emmerling, M. Fay, O. Fricko, S. Fujimori, M. Gidden, M. Harmsen, D. Huppmann, G. Iyer, V. Krey, E. Kriegler, C. Nicolas, S. Pachauri, S. Parkinson, M. Poblete-Cazenave, P. Rafaj, N. Rao, J. Rozenberg, A. Schmitz, W. Schoepp, D. Van Vuuren and K. Riahi, Nat. Energy, 2018, 3, 589-599.

4 J. B. Goodenough and K. S. Park, J. Am. Chem. Soc., 2013, 135, 1167-1176.

5 J. Janek and W. G. Zeier, Nat. Energy, 2016, 1, 1-4.

6 A. Manthiram, X. Yu and S. Wang, Nat. Rev. Mater., 2017, 2, 1-16.

7 K. Takada, J. Power Sources, 2018, 394, 74-85.
8 J. G. Kim, B. Son, S. Mukherjee, N. Schuppert, A. Bates, O. Kwon, M. J. Choi, H. Y. Chung and S. Park, J. Power Sources, 2015, 282, 299-322.

9 K. Takada, Acta Mater., 2013, 61, 759-770.

10 J. Li, C. Ma, M. Chi, C. Liang and N. J. Dudney, Adv. Energy Mater., 2015, 5, 1-6.

11 J. C. Bachman, S. Muy, A. Grimaud, H. H. Chang, N. Pour, S. F. Lux, O. Paschos, F. Maglia, S. Lupart, P. Lamp, L. Giordano and Y. Shao-Horn, Chem. Rev., 2016, 116, 140162.

12 P. E. de Jongh, D. Blanchard, M. Matsuo, T. J. Udovic and S. Orimo, Appl. Phys. A Mater. Sci. Process., 2016, 122, 1-6.

13 R. Mohtadi and S. I. Orimo, Nat. Rev. Mater., 2016, 2, 1-16.

14 M. Matsuo, Y. Nakamori, S. I. Orimo, H. Maekawa and

H. Takamura, Appl. Phys. Lett., 2007, 91, 2-5.

15 M. Matsuo and S. I. Orimo, Adv. Energy Mater., 2011, 1, 161172.

16 A. Unemoto, M. Matsuo and S. I. Orimo, Adv. Funct. Mater., 2014, 24, 2267-2279.

17 M. Matsuo, H. Oguchi, T. Sato, H. Takamura, E. Tsuchida, T. Ikeshoji and S. I. Orimo, J. Alloys Compd., 2013, 580, S98-S101.

18 K. T. Møller, D. Sheppard, D. B. Ravnsbæk, C. E. Buckley, E. Akiba, H. W. Li and T. R. Jensen, Energies, 2017, 10, 1645.

19 S. Kim, H. Oguchi, N. Toyama, T. Sato, S. Takagi, T. Otomo, D. Arunkumar, N. Kuwata, J. Kawamura and S. ichi Orimo, Nat. Commun., 2019, 10, 1-9.

20 L. Duchêne, R. S. Kühnel, D. Rentsch, A. Remhof, H. Hagemann and C. Battaglia, Chem. Commun., 2017, 53, 4195-4198.

21 R. Asakura, L. Duchêne, R. S. Kühnel, A. Remhof, H. Hagemann and C. Battaglia, ACS Appl. Energy Mater., 2019, 2, 6924-6930.

22 L. Duchêne, R. S. Kühnel, E. Stilp, E. Cuervo Reyes, A. Remhof, H. Hagemann and C. Battaglia, Energy Environ. Sci., 2017, 10, 2609-2615.

23 H. Oguchi, M. Matsuo, J. S. Hummelshøj, T. Vegge, J. K. Nørskov, T. Sato, Y. Miura, H. Takamura, H. Maekawa and S. Orimo, Appl. Phys. Lett., 2009, 94, 2-5.

24 H. Oguchi, M. Matsuo, T. Sato, H. Takamura, H. Maekawa, H. Kuwano and S. Orimo, J. Appl. Phys., 2010, 107, 105-108. 25 L. H. Rude, E. Groppo, L. M. Arnbjerg, D. B. Ravnsbæk, R. A. Malmkjær, Y. Filinchuk, M. Baricco, F. Besenbacher and T. R. Jensen, J. Alloys Compd., 2011, 509, 8299-8305.

26 L. H. Rude, O. Zavorotynska, L. M. Arnbjerg, D. B. Ravnsbæk, R. A. Malmkjær, H. Grove, B. C. Hauback, M. Baricco, Y. Filinchuk, F. Besenbacher and T. R. Jensen, Int. J. Hydrogen Energy, 2011, 36, 15664-15672.

27 M. Matsuo, H. Takamura, H. Maekawa, H. W. Li and S. I. Orimo, Appl. Phys. Lett., 2009, 94, 2-5.

28 R. Miyazaki, T. Karahashi, N. Kumatani, Y. Noda, M. Ando, H. Takamura, M. Matsuo, S. Orimo and H. Maekawa, Solid State Ionics, 2011, 192, 143-147.

29 Y. Yan, R. S. Kühnel, A. Remhof, L. Duchêne, E. C. Reyes, D. Rentsch, Z. Łodziana and C. Battaglia, Adv. Energy Mater., 2017, 7, 1-7. 
30 H. Maekawa, M. Matsuo, H. Takamura, M. Ando, Y. Noda, T. Karahashi and S. I. Orimo, J. Am. Chem. Soc., 2009, 131, 894-895.

31 D. Sveinbjörnsson, J. S. G. Myrdal, D. Blanchard, J. J. Bentzen, T. Hirata, M. B. Mogensen, P. Norby, S. I. Orimo and T. Vegge, J. Phys. Chem. C, 2013, 117, 32493257.

32 M. B. Ley, S. Boulineau, R. Janot, Y. Filinchuk and T. R. Jensen, J. Phys. Chem. C, 2012, 116, 21267-21276.

33 T. Mezaki, Y. Kuronuma, I. Oikawa, A. Kamegawa and H. Takamura, Inorg. Chem., 2016, 55, 10484-10489.

34 Z. Yao, S. Kim, K. Michel, Y. Zhang, M. Aykol and C. Wolverton, Phys. Rev. Mater., 2018, 2, 37-39.

35 D. Blanchard, A. Nale, D. Sveinbjörnsson, T. M. Eggenhuisen, M. H. W. Verkuijlen, S. Suwarno, T. Vegge, A. P. M. Kentgens and P. E. De Jongh, Adv. Funct. Mater., 2015, 25, 184-192.

36 S. Breuer, V. Pregartner, S. Lunghammer and H. M. R. Wilkening, J. Phys. Chem. C, 2019, 123, 5222-5230. 37 S. Das, P. Ngene, P. Norby, T. Vegge, P. E. de Jongh and D. Blanchard, J. Electrochem. Soc., 2016, 163, A2029-A2034. 38 M. H. W. Verkuijlen, P. Ngene, D. W. De Kort, C. Barré, A. Nale, E. R. H. Van Eck, P. J. M. Van Bentum, P. E. De Jongh and A. P. M. Kentgens, J. Phys. Chem. C, 2012, 116, 22169-22178.

39 N. Verdal, T. J. Udovic, J. J. Rush, X. Liu, E. H. Majzoub, J. J. Vajo and A. F. Gross, J. Phys. Chem. C, 2013, 117, 17983-17995.

40 Y. S. Choi, Y. S. Lee, D. J. Choi, K. H. Chae, K. H. Oh and Y. W. Cho, J. Phys. Chem. C, 2017, 121, 26209-26215.

41 S. F. H. Lambregts, E. R. H. Van Eck, S. Suwarno, P. Ngene, P. E. De Jongh and A. P. M. Kentgens, J. Phys. Chem. C, 2019, 123, 25559-25569.

42 Y. S. Choi, Y. S. Lee, K. H. Oh and Y. W. Cho, Phys. Chem. Chem. Phys., 2016, 18, 22540-22547.

43 P. Ngene, S. F. H. Lambregts, D. Blanchard, T. Vegge, M. Sharma, H. Hagemann and P. E. De Jongh, Phys. Chem. Chem. Phys., 2019, 21, 22456-22466.

44 J. Lefevr, L. Cervini, J. M. Griffin and D. Blanchard, J. Phys. Chem. C, 2018, 122, 15264-15275.

45 P. E. De Jongh and T. M. Eggenhuisen, Adv. Mater., 2013, 25, 6672-6690.

46 A. Gutowska, L. Li, Y. Shin, C. M. Wang, X. S. Li, J. C. Linehan, R. S. Smith, B. D. Kay, B. Schmid, W. Shaw, M. Gutowski and T. Autrey, Angew. Chemie, 2005, 117, 3644-3648.

47 D. T. Shane, R. L. Corey, C. McIntosh, L. H. Rayhel, R. C. Bowman, J. J. Vajo, A. F. Gross and M. S. Conradi, J. Phys. Chem. C, 2010, 114, 4008-4014.

48 P. Ngene, P. Adelhelm, A. M. Beale, K. P. De Jong and P. E. De Jongh, J. Phys. Chem. C, 2010, 114, 6163-6168.
49 A. Remhof, P. Mauron, A. Züttel, J. P. Embs, Z. Łodziana, A. J. Ramirez-Cuesta, P. Ngene and P. De Jongh, J. Phys. Chem. C, 2013, 117, 3789-3798.

50 P. N. Suwarno, A. Nale, T. M. Eggenhuisen, M. Oschatz, J. P. Embs, A. Remhof and P. E. De Jongh, J. Phys. Chem. C, 2017, 121, 4197-4205.

51 J. Maier, Prog. Solid State Chem., 1995, 23, 171-263.

52 C. C. Liang, J. Electrochem. Soc., 1973, 120, 1289.

53 R. Zettl, L. de Kort, M. Gombotz, H. M. R. Wilkening, P. E. de Jongh and P. Ngene, J. Phys. Chem. C, 2020, 124, 2806-2816.

54 R. Zettl, M. Gombotz, D. Clarkson, S. G. Greenbaum, P. Ngene, P. E. de Jongh and H. M. R. Wilkening, ACS Appl. Mater. Interfaces, 2020, 12, 38570-38583.

55 F. Lu, Y. Pang, M. Zhu, F. Han, J. Yang, F. Fang, D. Sun, S. Zheng and C. Wang, Adv. Funct. Mater., 2019, 29, 1-7.

56 C. F. Cheng, D. H. Park and J. Klinowski, J. Chem. Soc. Faraday. Trans., 1997, 93, 193-197.

57 H. I. Lee, J. H. Kim, G. D. Stucky, Y. Shi, C. Pak and J. M. Kim, J. Mater. Chem., 2010, 20, 8483-8487.

58 M. Baca, E. de la Rochefoucauld, E. Ambroise, J. M. Krafft, R. Hajjar, P. P. Man, X. Carrier and J. Blanchard, Microporous Mesoporous Mater., 2008, 110, 232-241.

59 S. Brunauer, P. H. Emmett and E. Teller, J. Am. Chem. Soc., 1938, 60, 309-319.

60 E. P. Barrett, L. G. Joyner and P. P. Halenda, J. Am. Chem. Soc., 1951, 73, 373-380.

61 T. Noritake, M. Aoki, S. Towata, A. Ninomiya, Y. Nakamori and S. Orimo, Appl. Phys. A Mater. Sci. Process., 2006, 83, 277-279.

62 G. P. Meisner, M. L. Scullin, M. P. Balogh, F. E. Pinkerton and M. S. Meyer, J. Phys. Chem. B, 2006, 110, 4186-4192.

63 Y. Yan, J. B. Grinderslev, Y. S. Lee, M. Jørgensen, Y. W. Cho, R. Černý and T. R. Jensen, Chem. Commun., 2020, 56, 39713974.

64 V. D'Anna, A. Spyratou, M. Sharma and H. Hagemann, Spectrochim. Acta Mol. Biomol. Spectrosc., 2014, 128, 902-906.

65 J. P. O. Bohger, R. R. Eßmann and H. Jacobs, J. Mol. Struct., 1995, 348, 325-328.

66 B. A. Morrow and A. J. McFarlan, J. Phys. Chem., 1992, 96, 1395-1400.

67 A. G. Merzhanov, V. V. Barzykin, A. S. Shteinberg and V. T. Gontkovskaya, Thermochim. Acta, 1977, 21, 301-332.

68 D. Zhao, J. Feng, Q. Huo, N. Melosh, G. H. Fredrickson, B. F. Chmelka and G. D. Stucky, Science, 1998, 279, 548-552.

69 D. Zhao, J. Sun, Q. Li and G. D. Stucky, Chem. Mater., 2000, 12, 275-279.

70 I. Chorkendorff and J. W. Niemantsverdriet, Concepts of Modern Catalysis and Kinetics, John Wiley \& Sons, Weinheim, 2nd edn, 2003. 